\title{
Research on Wood Materials and the Thermal Environment of Dwellings
}

\author{
Liping Li, Shuai Fan \\ Department of Architecture, Faculty of Architecture and City Planning, \\ Kunming University of Science and Technology, Kunming , China \\ Ilping402@163.com, fs1204@sina.com
}

\begin{abstract}
Keywords: Dwellings; wood materials; temperature; test and analysis
Abstract. Under the circumstances of backward production tools and technologies, varied and graceful local buildings are built by using the local materials with the wisdom of the working people. The article analyzed wood dwellings in Xishuangbanna in Yunnan Province as cases. Based on the field testing and analysis of the wood dwelling in Xishuangbanna, and more specifically, the indoor temperature of the dwellings with wood walls as well as the surface temperature of building envelope were tested and comparatively analyzed. The test results reveal that the maximum and the minimum of the indoor air temperature is $1.1^{\circ} \mathrm{C}$ and $0.1{ }^{\circ} \mathrm{C}$ lower than one of the outdoor temperature, an amplitude of the indoor air temperature is $1.0^{\circ} \mathrm{C}$ lower than one of the outdoor temperature. The test results show the current situations and features of indoor temperature changes of these dwellings of wood materials, which may provide a basis for improving the thermal environment of Dai nationality dwellings.
\end{abstract}

\section{Introduction}

Under the circumstances of backward production tools and technologies, varied and graceful local buildings are built by using the local materials with the wisdom of the working people. Under the local climate and environment, unique building types that are harmonious with the natural environment are built. In these buildings, there are many "green" construction ideas and technologies. In the previous researches on local buildings, it is analyzed mainly from the formation of ancient settlement, the types of buildings, landscape and the manifestation of buildings as the carrier of culture, etc. As for the survey on the local buildings of the Dai nationality in Xishuangbanna this time, these dwellings are analyzed and researched mainly from building technology and the indoor thermal environment testing of building, etc.

Jinghong in Xishuaibanna, with an elevation of $530 \mathrm{~m}$, belongs to the cold climate region (IV) according to the Standard of Climatic Regionalization for Architecture (GB50178-93) [1] [2] and Thermal Design Code for Civil Building (GB 50176-93) [3]. The average temperature ranges from $18^{\circ} \mathrm{C}$ to $21.8^{\circ} \mathrm{C}$, the air temperature of 38 degrees in summer. This area features particularly hot and wet, as shown in Fig.1.

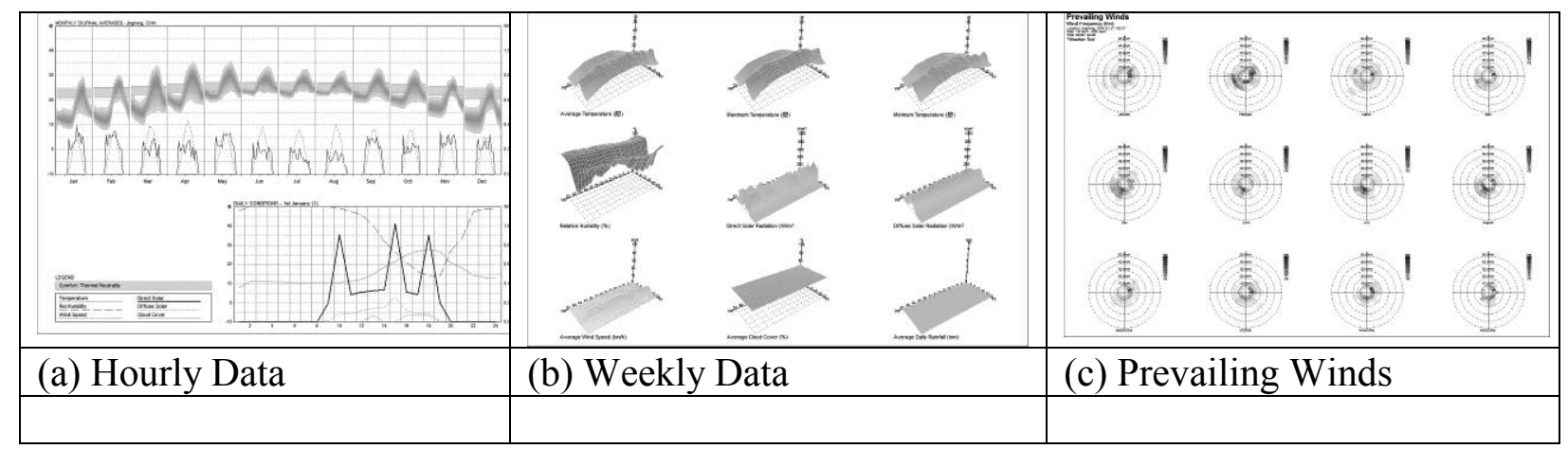




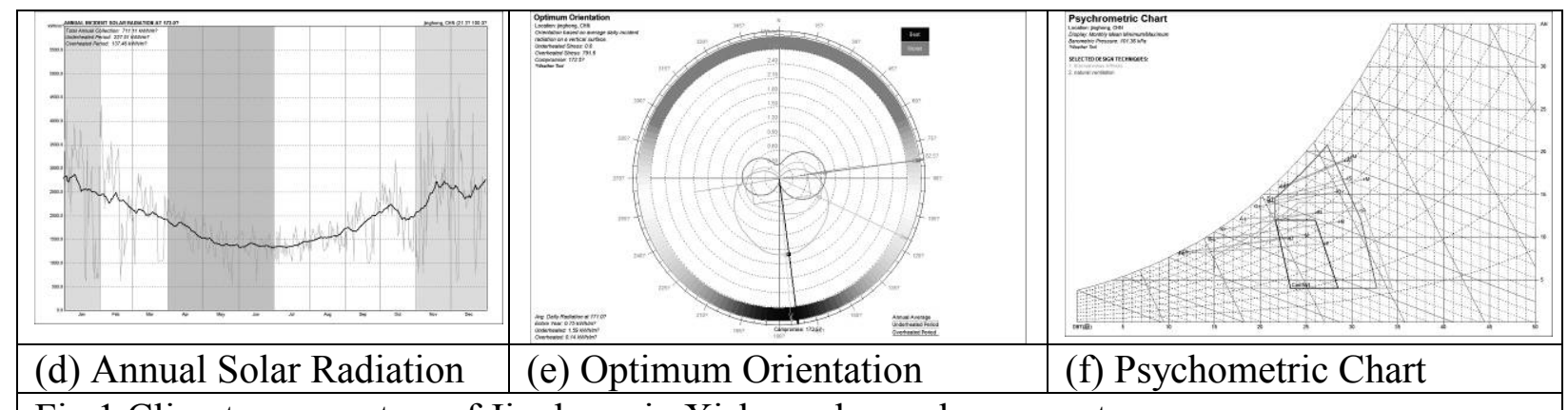

Fig.1 Climate parameters of Jinghong in Xishuangbanna by computer

\section{Basic Information on Buildings}

In order to understand the current situations of indoor thermal environment of Dai nationality dwellings of different materials in Jinghong of Xishuangbanna, we tested on such parameters as indoor temperature of Dai nationality dwellings with wood walls and the surface temperature of building envelope in 2006, and found out the changes rules and features of the test parameters through comparative analysis, which provides a necessary actual measurement basis for improving the comfort of indoor thermal environment of Dai-style dwellings in summer.

The dwelling is located forty kilometers from Jinghong in Xishuangbanna. It is tile-roofed houses with wood structure. The dwelling is as shown in Fig.2, Fig.3. From picture, dwelling is a traditional Dai nationality dwelling in the south-north orientation, which is of square shape in plane and has a living room, several rooms, a storage, a corridor. It is with 2.5 meters of first floor height and 3.0

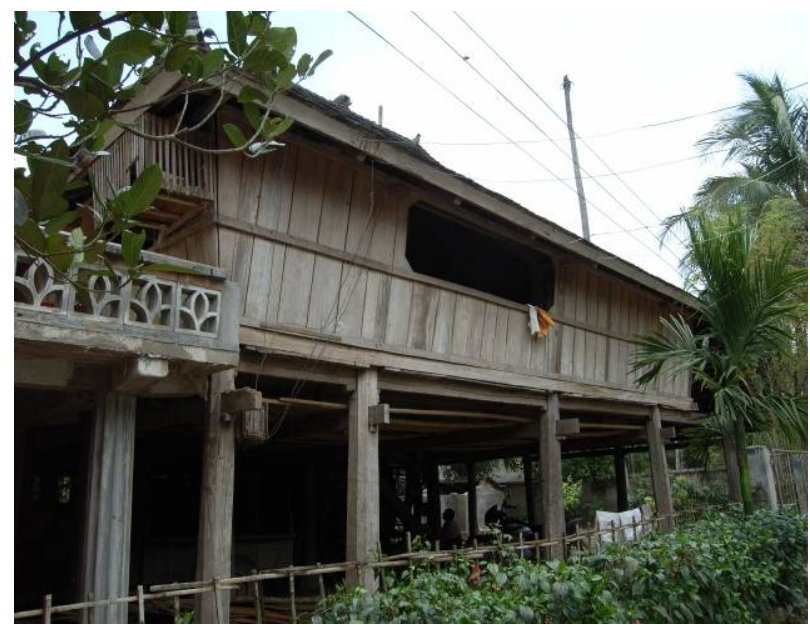

Fig.2 Dai nationality wood dwellings

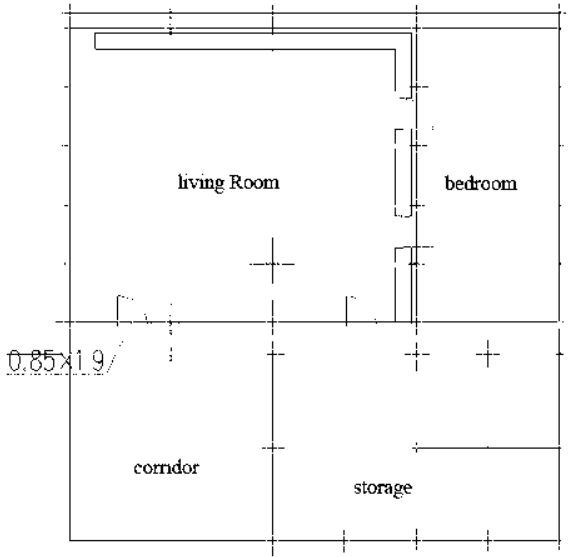

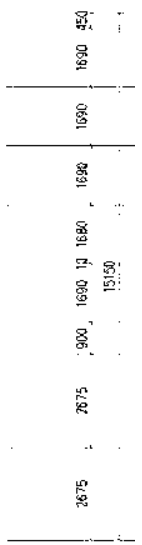

Fig.3 Plan of the 2nd Floor

meters of second floor height. The walls of this dwelling are wood walls, and a wall nearby a corridor. The pillars has support the floor in 1st floor, and no wall around, which is beneficial for natural ventilation and reduces the heat in summer. The 2 nd floor is main space where the Dai nationality lives, which is of square shape in plane with a living room and bedrooms. The corridor on the 2 nd floor is also open. The roof is Jehiel mountain type clay tile roofs

\section{Test Methods, Test Instruments and Layout of Testing Points}

The tests were carried out continuously for 48h during May 4-6, 2006, which started from 07:48 till 06:48 of the day after tomorrow, with an interval of $1 \mathrm{~h}$. To reduce the measurement error, all test instruments had been calibrated prior to the test. The tests were carried out in summer, during which this area featured cold night and strong solar radiation in the daytime outdoors, and it had a highest 
outdoor temperature of $37.7^{\circ} \mathrm{C}$ and a lowest temperature of $23.5^{\circ} \mathrm{C}$ at the place with a high of $1.5 \mathrm{~m}$. Thus this day may represent the typical outdoor climate of Xishuangbanna in summer.

Raytek RayngerST infrared thermometer manufactured by America was used for measuring the temperature, with the measurement ranging from $-32^{\circ} \mathrm{C}$ to $535^{\circ} \mathrm{C}$ and a precision of $0.1^{\circ} \mathrm{C}$, which may be used for measuring the surface temperature of the ground, wall and roof. Moreover, UNITEC MCT-111 portable digital thermometer manufactured by Unite Technique Development Company was adopted for measuring the indoor and outdoor air temperature, with the measurement ranging from $-200^{\circ} \mathrm{C}$ to $400^{\circ} \mathrm{C}$ and a precision of $0.1^{\circ} \mathrm{C}$, which has 0.1 resolution within the scope of $-200^{\circ} \mathrm{C}--200^{\circ} \mathrm{C}$.

Layout of testing points: according to the situations of stone dwellings, the testing points were arranged at the middle of the rooms about $1.5 \mathrm{~m}$ above the ground to measure the air temperature; and at the middle of the surface of building envelopes of different materials for measuring the surface temperature

\section{Test Results and Research Analysis}

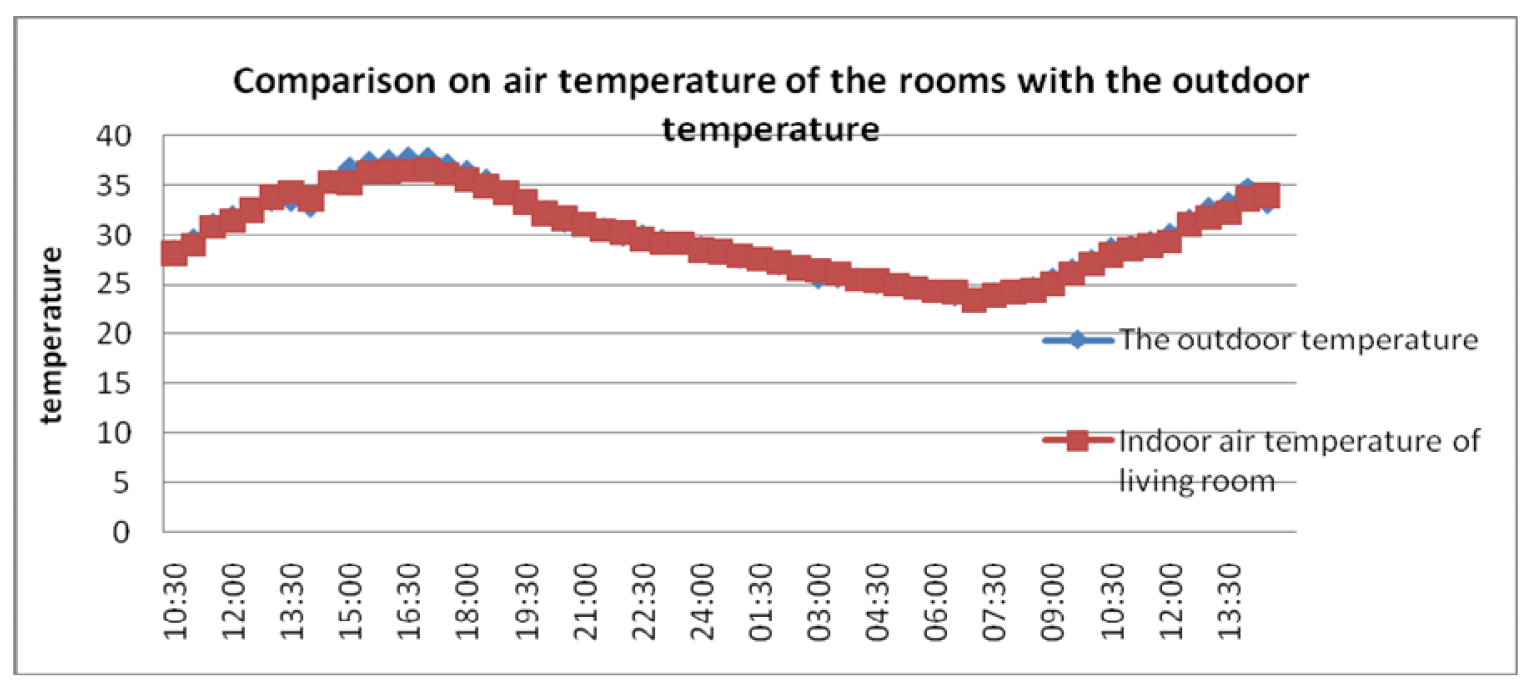

Fig.4 Comparison on air temperature of the rooms with the outdoor temperature

As shown in Fig.4 and Table 1, in the rooms of Dai nationality wood dwelling ,the outdoor temperature reached the peak of $37.7^{\circ} \mathrm{C}$ at $16: 30 \mathrm{p} . \mathrm{m}$., while the indoor air temperature arrived at the maximum of $36.6^{\circ} \mathrm{C}$ at 17:00 p.m. The maximum of the indoor air temperature is $1.1^{\circ} \mathrm{C}$ lower than one of the outdoor temperature. The minimum of the outdoor temperature was $23.5^{\circ} \mathrm{C}, 0.1^{\circ} \mathrm{C}$ lower than one of the indoor air temperature which was $23.4^{\circ} \mathrm{C}$. On the day when we carried out the measurement, the fluctuation scope and range of outdoor temperature are from $23.5^{\circ} \mathrm{C}$ to $37.7^{\circ} \mathrm{C}$, with an amplitude of $14.2{ }^{\circ} \mathrm{C}$, while the indoor air temperature fluctuated from $23.4{ }^{\circ} \mathrm{C}$ to $36.6{ }^{\circ} \mathrm{C}$, with an amplitude of $13.2{ }^{\circ} \mathrm{C}$. It is clear that the fluctuation range of outdoor temperature is much larger than that of indoor air temperature.

Table 1.Comparison of the indoor air temperature with the outdoor temperature

\begin{tabular}{|l|l|l|l|l|}
\hline & \multicolumn{2}{|l|}{$\begin{array}{l}\text { maximum temperature } \\
{\left[{ }^{\circ} \mathrm{C}\right]}\end{array}$} & $\begin{array}{l}\text { minimum temperature } \\
{\left[{ }^{\circ} \mathrm{C}\right]}\end{array}$ \\
\hline The outdoor temperature & 37.7 & 23.5 \\
\hline $\begin{array}{l}\text { Indoor air temperature in the wood } \\
\text { dwellings }\end{array}$ & 36.6 & 1.1 lower & 23.4 & 0.1 lower \\
\hline
\end{tabular}




\section{Conclusion}

It can be concluded from the comparison of the indoor air temperature of Dai traditional wood dwelling with the outdoor temperature :

[1] The test results also show that pillars has support the floor in 1st floor, and no wall around, which is beneficial for natural ventilation and reduces the heat in summer.

[2] The maximum of the indoor air temperature is $1.1^{\circ} \mathrm{C}$ lower than one of the outdoor temperature. The minimum of the indoor air temperature is $0.1{ }^{\circ} \mathrm{C}$ lower than one the outdoor temperature.

[3] An amplitude of the indoor air temperature is $1.0^{\circ} \mathrm{C}$ lower than one of the outdoor temperature.

\section{Acknowledgements}

Project Supported by Yunnan Provincial Natural Science Foundation of China: Research on the Sustainable Development in Buildings with Different Geographic and Climate Resources and Environment in Yunnan (2003E0026M)

\section{References}

[1] Design standard for energy efficiency of civil buildings (DBJ53/T-39-2011), in Chinese.

[2] Standard of Climatic Regionalization for Architecture (GB50178-93), in Chinese.

[3] Thermal Design Code for Civil Building (GB 50176-93), in Chinese.

[4] Ministry of Housing and Urban-Rural Development of the People's Republic of China. Typological Collection of Traditional Chinese Dwellings [M]. Beijing: China Architecture and Building Press, 2014

[5] [British] Brian Edwards. Sustainable Buildings(2 ${ }^{\text {nd }}$ edition) [M]translated by Zhou Yupeng and Song Huahao et al., Beijing: China Architecture and Building Press,2003 